\title{
COVID-19 and Educational Consequences for (Vulnerable) Children from the Perspectives of Educational Psychologists
}

\author{
Thomas Szulevicz ${ }^{1}$ iD
}

Received: 4 January 2021 / Revised: 15 March 2021 / Accepted: 7 April 2021

(c) The Author(s), under exclusive licence to Springer Nature Switzerland AG 2021

\begin{abstract}
The COVID-19 represents an unprecedented global interruption of education that leaves us with an abundance of unanswered questions related to the consequences of the pandemic and of the lockdown and school closure for children. In the article, I argue that we have seen two different approaches to the pandemic in relation to education and to understanding children and vulnerable children. The first approach emphasizes how pre-existing vulnerabilities have been worsened and exacerbated. From this perspective, the pandemic has exposed and amplified existing educational inequalities and made tacit structures of power and control more visible. The second approach acknowledges the consequences of the pandemic, but it also considers the current crisis as an opportunity to build back better. From this perspective, we are urged to use the pandemic as an opportunity to rethink education in more equitable ways. Based on qualitative interviews with educational psychologists (EPs), this article sheds light on these two different approaches and on some of the consequences of the COVID-19 pandemic regarding vulnerable children and educational inequalities from the perspectives of EPs.
\end{abstract}

Keywords COVID-19 · Educational psychology · Vulnerable children · Resilience · Inequality

\section{Introduction}

According to a recently published UNESCO report on inclusion and education (UNESCO, 2020), the COVID-19 pandemic has exposed and deepened global and educational inequalities. In the foreword of the report, general director of UNESCO, Audrey Azoulay, describes how the pandemic brought massive and sudden changes in schools around the globe:

With more than 90 per cent of the global student population affected by COVID-19 related school closures, the world is in the throes of the most unprecedented disruption in the history of education. (UNESCO, 2020: IIII).

Thomas Szulevicz

thoszu@hum.aau.dk

1 Department of Communication and Psychology, Aalborg University, Aalborg, Denmark 
Such an unprecedented global interruption of education obviously presents significant challenges for students, families, and teachers. But it also leaves us with an abundance of unanswered questions related to the consequences of the lockdown and school closure on children's needs, children's learning options, children's physical and mental well-being, teachers' working conditions, and parents' role in supporting their children etc. As stated in the UNESCO report, global crises like COVID-19 tend to exacerbate existing inequalities, and while there seems to be a general recognition of the crucial role of social and cultural inequalities, the current crisis still has the potential to raise new questions, generate new knowledge, and reevaluate our existing knowledge about inequalities in schools.

Based on interviews with Danish educational psychologists (EPs), this article sheds light on some of the consequences of the COVID-19 pandemic regarding vulnerable children and educational inequalities from the perspectives of educational psychologists.

The current status (January 2021) is that the WHO anticipates a lengthy duration of the COVID-19 pandemic (Banerjee, 2020), and if we are to fully understand the extremely complex social and educational processes during the pandemic, more in-depth knowledge is needed. Despite the fact that EPs have extensive professional knowledge and expertise regarding children with and without special needs and vulnerable students and students at risk of social and academic marginalization, their perspectives on and their understandings of the consequences of the pandemic have been surprisingly understudied. EPs are in frequent contact with vulnerable children and their families. They know their teachers and their schools, and EPs have a rich and cross-contextual understanding of children and their everyday lives. Furthermore, they are experts in facilitating supportive learning environments for students in general and for students with special needs more specifically.

Understanding the consequences of the COVID-19 from the perspectives of educational psychologists is interesting as they are in frequent contact with schools, institutions, parents, and vulnerable and marginalized children. EPs thus have cross-contextual insight in both children with and without special needs, and many EPs were in frequent contact with children, parents, teachers, schools, and institutions during the lockdown and reopening of schools, and EPs can therefore give important perspectives on the psycho-educational consequences of the pandemic.

\section{Reproduction of Inequalities and Difficulties or an Opportunity to Build Back Better?}

In a recent paper, Lupton (2020) contextualizes the COVID-19 pandemic from a sociocultural perspective. Lupton argues how the crisis can be seen as a mirror to our society and that it urges us to raise new questions, generate new knowledge, and reevaluate our existing ways of knowing. From this perspective, the pandemic is a sociocultural phenomenon "... infused with and understood through situated and shifting meanings and practices." (Lupton, 2020, 1). Historically, the sociocultural dimensions of other pandemics (like the Black Death or the HIV/AIDS crisis) have attracted great attention as aspects of our society that usually are taken for granted can be seen in a new light. Often, pandemics expose and amplify inequalities and make tacit structures of power and control more visible, which also was a theme in Camus's (1947/1996) highly topical existentialist novel "The Plague" (La Peste) from 1947 in which he depicted a plague that stroke the French Algerian city of Oran sometime in the 1940s. Camus depicts the plague as a philosophical notion of the absurd and a metaphor for the Nazi invasion of 
France. In the novel, we learn about the administrative mismanagement of the plague, and how the plague is dealt with by the press, the church, and the local authorities, and the novel asks questions about humanity and the meaning and values of society in times of crisis.

The current pandemic is obviously a sociocultural phenomenon in which virus spreading becomes "pandemic" as a social representation. But it is also an educational phenomenon as far as the pandemic has widespread educational consequences. I will argue that two different approaches to the educational consequences of the COVID-19 pandemic seem to have materialized.

The first and probably most widespread approach is the one described in the already mentioned UNESCO report in which it is emphasized how the COVID-19 pandemic deepens existing inequalities.

To understand this approach, Bourdieu's Theory of Practice (Bourdieu, 1986; Bourdieu \& Wacquant, 1992) is helpful as it highlights how different practices like for example school activities are the result of a complex interplay between people's habitus (dispositions), their capital (Bourdieu stressed the importance of including not only economic but also social and cultural resources to determine one's status and position in society), and field (circumstances) (Akkermans et al., 2020). According to Bourdieu (1986), the educational system produces and reproduces hegemonic cultural and linguistic forms of power and knowledge. And as it most often happens in times of crises, these forces have been reinforced and strengthened with the current pandemic widening economic, cultural, social, and educational vulnerability for marginalized populations, those with less education, and those with special educational needs.

From Bourdieu and countless studies, we know that schools reproduce existing inequalities and contribute to social reproduction. But we also know that schools can help reduce the effects of social inequality. For the most vulnerable children, schools provide a structured setting that during the temporal school lockdown was inaccessible. During the lockdown, many children stayed at home with parents who were unable to support them sufficiently for different social, economic, cultural, or academic reasons (Brown et al., 2020). Blundell et al. (2020) for example describe how poorer families have been receiving less support from schools during the lockdown, whereas parents in better-off families and with higher levels of education were more likely to work from home and to have space and resources to help educate their children. Blundell et al. (2020) further describe how the school lockdowns might produce long-lasting learning outcome effects as schools under normal circumstances represent an equalizing force that was suspended during the lockdown, where families assumed a much larger share of the responsibility for educating their children.

We have, however, also seen the emergence of another approach to the COVID-19 pandemic. This approach obviously also acknowledges how the pandemic has been a massive and completely unforeseen disruption of education. From this perspective, the pandemic also represents an opportunity to "build back better" as the pandemic has shown how communities can come together, how technology can be used to overcome learning barriers, and how we can overcome the climate crisis (Iyengar, 2020). The pandemic thus offers possibilities for post-pandemic transformations and for rethinking development and ways of organizing existing societal and educational structures (Leach et al, 2021).

In the same spirit, Arnove (2020) argues that the pandemic's disproportionate consequences underscore institutionalized and structural forms of discrimination that no longer should be accepted. Arnove urges educational systems to use the pandemic as an opportunity to rethink education in more equitable ways. The pandemic has thus revealed existing educational inequalities that simply should not be accepted in the future. 
Although the COVID-19 pandemic seems to have affected persons with special needs disproportionally as many of these students thrive in predictability and have a hard time dealing with unforeseen changes, evidence also suggests that some of these children are even doing better with the social distancing and restrictions of the pandemic. Pesch et al. (2020) describe:

However, a sizable subset has been described as thriving while social distancing. Even without school supports, private therapies, or in-person visits, some children are seemingly doing better than ever. In our practices, we have observed this in children who are socially anxious or rigid or who struggle with transitions or learning. The mother of an 8-year-old boy with learning disabilities, attention deficit hyperactivity disorder, and anxiety recently reported in a telehealth visit 'I'm the least worried about him that I have been in years. He's thriving at home, he's happy and relaxed." (Pesch et al., 2020: 506).

Based on survey data from 5953 Danish children (from 3rd to 9th grad, aged 9-16) and 5054 parents collected in April 2020, a Danish survey (Qvortrup et al., 2020a) also indicated that many children-despite the difficult circumstances-were thriving during the lockdown, and that some had strengthened close relationships and found new ways to be together online.

To sum up, I thus argue that we see two different approaches to the pandemic in relation to children and vulnerable children, one approach that emphasizes how pre-existing vulnerabilities have been worsened and a second approach that acknowledges the consequences of the pandemic, but also considers the current crisis as an opportunity to build back better.

\section{The School Lockdown in Denmark}

In Denmark, the lockdown due to the COVID-19 pandemic was announced March 112020. All people working in non-essential functions in the public sector were ordered to stay home or work from home. Likewise, employers who did not perform critical functions in the private sector were urged to allow their employees to stay home in the same period. All secondary education, universities, libraries, indoor cultural institutions, and similar places were also closed. The municipalities established limited daycare for children where the parents could not stay home and take care of them.

During the lockdown, children were obliged to participate in distance learning as schools were responsible for compulsory education. The sudden lockdown required quick adjustments from teachers, parents, and children with parents working from home while taking care of their children's school activities. These changes obviously took a massive toll on schools and families with the development of new educational teaching strategies for online learning as one of the most prominent features. In the blink of an eye, students' everyday lives changed dramatically with all school and social activities being cancelled or transported to video calls and digital platforms.

Following a 1-month lockdown, Denmark was one of the first European countries to announce a gradual easing of restrictions, and by April 15, early childhood education and care, primary education up to fifth grade, senior year students in general, upper secondary education, and special needs schools reopened.

In general, the reopening was considered a very challenging and divisive issue. Certain conditions were imposed on nurseries, kindergartens, and schools such as frequent 
cleaning of surfaces, hand-washing, requirements of smaller class sizes, and a regulated distance of $2 \mathrm{~m}$ between desks.

To reduce wide-scale virus transmission within schools, the reopening involved reductions of class size (with approximately $50 \%$ capacity) and increasing of social distance with students kept in defined groups and with limited interaction between groups. No face masks were required for students or teachers. As already described, primary school children were the first to return to school, and students were kept in small groups with minimal contact with others outside their group. Students were organized in groups of approximately 12 students to ensure sufficient physical distance between students and teachers. During breaks, students were allowed to play only in small groups. During April, May, and June, the school reopening in Denmark did not result in a significant increase in the growth rate of COVID-19 cases.

Although preliminary data suggests that most Danish students handled the lockdown and reopening of schools relatively well (Qvortrup et al., 2020b), the lockdown, the reopening of schools, and the general consequences of the pandemic clearly have affected children in varied ways. Some children have parents who have suffered serious economic losses because of the pandemic, other parents are now unemployed because of the economic damage of the pandemic (Lawson, 2020), and some children have even lost relatives to the virus. And although children are at low risk for the morbidities and mortalities associated with COVID-19 (Hoffman \& Miller, 2020), many children were marked by anxiety related to the virus.

Qvortrup et al. (2020b) found that social distancing was the factor that affected students most negatively during the lockdown. In general, children missed their daily grind in school, with friends and social activities. To support this, more than $90 \%$ reported to miss their friends and their social activities, while more than $50 \%$ of the students reported that they did not feel happy. Approximately, $70 \%$ of the students missed teaching, while $60 \%$ of the students missed their teachers. One fifth of the students felt lonely during the lockdown. According to the authors of the Danish study, this already high prevalence of loneliness was kept down by the fact that families in general compensated for the missing after school activities by spending more time together. Nevertheless, student well-being was markedly lower during the lockdown compared with data from the yearly national Danish well-being survey in schools. As for online schooling, most students, parents, and teachers seemed to make a great effort to get teaching and learning activities up and running with most students having fairly clearly structured plans for the different daily school activities. However, and not surprisingly, a share of students had a difficult time structuring the school activities as some were dependent on special needs educational activities, and/or left with minimal parental help. Some of these students also reported having motivational problems. Another interesting finding from the survey was that online teaching in general was more teacher directed with less active student participation. Only $25 \%$ of the students were engaged in group work (which is a low share in a Danish educational context that usually puts great emphasis on group work).

As for the parents, approximately $50 \%$ of the respondents described how it was difficult to find a fair work/life/home school balance. In general, both students and parents were satisfied with the ways schools transitioned to online learning activities with approximately $70 \%$ of both parents and students reporting being satisfied with the way the teachers handled the lockdown and their online teaching (Qvortrup et al., 2020b). 


\section{Background and Method}

At the time of writing (January, 2021), a lot of research that deals with students' coping procedures during the school closures is being published, and the aim of this article is not to review this research literature. However, it is noteworthy to underline how it globally has been indicated that compared to adults, the current pandemic might have increased long-term negative consequences on children and adolescents (Singh et al., 2020). Furthermore, the impact of the potential negative consequences depends on different (vulnerability) factors like age, educational status, socioeconomic status of the family, having special educational needs, and pre-existing mental health condition. The current status is that the WHO anticipates a lengthy duration of the COVID-19 pandemic (Banerjee, 2020), and if we are to fully understand the extremely complex social and educational processes during the pandemic, more in-depth knowledge is needed. It is of crucial importance that multifaceted understandings of the consequences of the pandemic are developed. Despite the fact that EPs have extensive professional knowledge and expertise regarding children with and without special needs and vulnerable students and students at risk of social and academic marginalization, their perspectives on and their understandings of the consequences of the pandemic have been surprisingly understudied. EPs are in frequent contact with vulnerable children and their families. They know their teachers and their schools, and the educational psychologists thus have a rich and cross-contextual understanding of children and their everyday lives. Furthermore, they are experts in facilitating supportive learning environments for students in general and for students with special needs more specifically.

The objective of this research was to analyze the educational consequences for (vulnerable) children of the school lockdown and subsequent reopening from the perspectives of educational psychologists. The term "vulnerability" is used very broadly, and I am inspired by Schroeder and Gefenas' (2009) definition: "To be vulnerable means to face a significant probability of incurring an identifiable harm while substantially lacking ability and/ or means to protect oneself (Schroeder \& Gefenas, 2009: 117). I am thus not referring specifically to children who are diagnosed with childhood disorders or children from disadvantaged families. On the contrary, the aim of the research is to shed light on how the pandemic can teach us something new about the understanding of children and vulnerability.

The study uses a qualitative approach to understand the impact of COVID-19 on children's and vulnerable children's lives. Potential participants were recruited through a closed national Danish website for educational psychologists. A brief description of the research project was uploaded, and seven EPs (six female and one male) volunteered to participate in in-depth qualitative semi-structured interviews. I got positive feedback from many EPs about the research topic. Due to an increased workload during their time working at home and from the reopening of institutions and schools, many of the EPs opted, however, not to participate in the interview.

The seven recruited EPs all worked in different public educational psychology service centers. Although there are some differences in the organization and administration of educational psychology service centers across Denmark, they are generally quite similar, and they follow the same legislative procedures.

All interviews were conducted by the principal investigator and based on an interview guide. The interview guide was identical for all seven interviews.

Due to social restrictions, the interviews were converted to a teleconferencing technology. The interviews lasted between $1 \mathrm{~h}$ and $1 \frac{1}{2} \mathrm{~h}$, and they were transcribed verbatim within a month. The interviews were conducted in the beginning of June 2020-approximately 
1 month after the reopening of nurseries, daycares, and schools. The interview guide both had questions dealing with the school closure and the initial reopening.

The analysis of the empirical material focuses on the interviewed EPs' (1) perceptions and understandings of vulnerable children and (2) what the school closure and initial reopening taught EPs about their function as EPs and about vulnerable children.

The transcripts were organized and coded according to strategies of meaning condensation, systematic text condensation, and open coding (Malterud, 2012). The open coding took form as an inductive approach that examined the repetition of phrases, words, and key constructs moving back and forth from specific to general themes that emerged from the coded transcripts.

\section{Empirical Results}

The empirical results of the analysis will be presented in two different phases: (1) the lockdown and (2) the reopening.

\section{Phase 1-the Lockdown}

All seven interviewed EPs had been sent home working, as none of them performed critical functions.

Most of them only had a few phone calls or Skype meetings a day during the lockdown. Otherwise, their time was primarily spent writing psychoeducational reports and completing administrative tasks.

From the analysis of the transcribed interviews, two sub-themes emerged:

1. School closure carried huge costs for children from disadvantaged families

2. The lockdown as a welcome break from school

\section{Sub-theme 1: School Closure Carried Huge Costs for Children from Disadvantaged Families}

While the EPs generally described a quite great variation in their experiences of the school closure, a common-and not surprising-pattern in their descriptions was that children from disadvantaged homes had a hard time during the lockdown. Some of the interviewed EPs carry out work in special schools for some of the most marginalized and vulnerable children from socially disadvantaged families. One of these EPs expressed:

My clear impression is that many children who went to general or mainstream schools actually benefitted from the lockdown, while children from the most disadvantaged families really suffered. Many of these children's parents simply don't have surplus energy to take care of their children, and it got even worse during the lockdown. Some parents even rang me and said that they couldn't afford lunch for their own children.

Another EP reported that she talked with a boy:

He told me that he had only been outside of his house twice during the lockdown. The rest of the time, he stayed at home, played computer or was just lying in his bed. 
His parents started drinking more and more, and they took drugs. It is really harsh conditions for a child.

According to another EP, some parents also passed down their fear of the virus to their children and thereby affecting their wellbeing and mental health negatively:

If you live in such a family, the school closure has a very negative effect on wellbeing, because the parents actually pass down their own anxiety to the children, and the child is left alone with these feelings that are difficult to understand and cope with.

During the interviews, the EPs described a clear pattern, where the majority of the children from the most disadvantaged families only experienced minimal or no parental involvement in the homeschooling. Furthermore, these children seemed to be more isolated from virtual contact with their classmates, and they also seemed to have less contact with their teachers compared to many of their peers.

\section{Sub-theme 2: the Lockdown as a Welcome Break from School}

A recurrent theme through the interviews was that the interviewed psychologists described that most of the students both with and without special needs-with the exception of the most vulnerable children-tackled the lockdown surprisingly well. It is, however, important to bear in mind that the first lockdown in Denmark was short compared to many other countries, which might explain the relatively positive evaluation of the lockdown. An EP for example described:

I have a special class for children with autism spectrum disorders, and they really enjoyed the lockdown, and the parents enjoyed the lockdown so much that they were reluctant to send their kids back to school again. The kids enjoyed having their parents around, they enjoyed the predictability and daily routine during the lockdown.

One of the interviewed EPs is specialized in working with children with long-term school-absenteeism. She described how some of these children had more contact with the schools and participated more in school activities (online teaching) during school closures than before the lockdown. She described how a 15-year old girl told her that she no longer felt like an outsider as she was participating in teaching in the same way as her peers.

During the interview, the same EP told:

I have a boy who wets his pants in school. Under the lockdown, he completely stopped wetting the pants, but when he started in school after the reopening his problems were back again.

The EPs thus described how the lockdown became an oasis and a welcome break for some students.

As a consequence of the gradual reopening of schools in Denmark, students from 6th grade and up were homeschooled an extra month, and one of the interviewed EPs described how time was becoming a factor.

I really got the impression that many of the older students started feeling lonely or bored at the end of the lockdown, and I was very happy when they opened the schools for them as well.

If the lockdown initially represented a welcome break from schools, the prolonged school closures for the elder Danish students clearly started having some negative consequences in 
terms of social isolation, boredom, and feelings of loneliness. This also indicates that the initial honeymoon phase, where families came together and fought against the virus quite quickly, came to an end. Nonetheless, the fact that the interviewed EPs described a pattern in which a substantial share of children clearly benefitted from the school closures should be taken as an opportunity to consider how school cultures might have damaging effects on students' wellbeing, and how school cultures can be reshaped to be more supportive in the future.

One of the things that many families and children actually enjoyed, was how the virus slowed everything down and forced families to spend more time together. Many families live their lives at breakneck speed, but the shutdown suddenly halted everything. Parents had more time with their children, and I am convinced that this had a positive impact on children wellbeing.

A related and common theme across the interviews is how the general slowing down of activities not only had positive environmental effects but also interpersonal and mental ones. While the outbreak of the virus obviously felt stressful for many families with raised levels of conflict, the EPs generally reported how the lockdown and the general slowing down of normal everyday life were beneficial for many children and their families.

Another EP described:

A girl told me how there were less conflicts in her family. But I also noticed how the lockdown affected my own family life. For the first time in years, we did not feel like being part of the rat race, which basically felt like a great relief. This has made me think that we underestimate children's need for rest and relaxation, and that we tend to over-schedule children's lives.

Many families obviously felt pressured at home during the lockdown with homeschooling, and children from the most disadvantaged families most probably did not experience the benefits of less scheduled everyday lives. It is, nonetheless, noteworthy how it was a commonly held view among the interviewed EPs that the slowing down of activities had some unforeseen positive effects:

I was in contact with a family who has a son with ADHD. At first, we were all worried about how they would tackle the homeschooling and lockdown. Initially, they were extremely stressed and anxious about the whole situation. But slowly, they found a rhythm and actually ended up appreciating what they found to be a less hectic everyday life.

As with the previous empirical examples, the duration and length of the lockdown is an important factor to bear in mind as some of the qualities of a less scheduled everyday life might decrease over time.

Some of the interviewed EPs also emphasized how many students felt less academic pressure during the lockdown, which seemed to have a positive effect on some of the students with long-term school absenteeism.

\section{Phase 2: Reopening}

Three sub-themes once again emerged from the analysis of the transcribed interviews:

1. The number of students per class matters 
2. The deregulated school

3. Resilience is an educational matter

\section{Sub-theme 1: the Number of Students Per Class Matters}

As previously described, the lockdown only lasted 1 month for the youngest children and students in Denmark, who were back in school by April 15. The reopening involved marked reductions of class size with only $50 \%$ capacity to increase social distance in each classroom. Throughout the seven interviews, it was stressed how the reduced class size resulted in less conflicts, less disruptions in teaching, markedly improved student wellbeing, and improved teacher job satisfaction. Despite the difficult circumstances, with precautionary measures and restrictions, the EPs agreed that the reduced class size had a very positive effect on the learning environment during the first month after the reopening of schools. One EP expressed:

I was almost left shocked by the positive impact of the reduction of class size. Everything just seemed more relaxed with teachers having more time and mental resources to teach.

In some Danish authorities, EPs were asked to act as assistant teachers during the reopening of schools as the reduced class size resulted in teacher shortage. As a consequence, two of the interviewed EPs worked as assistant teachers for about 4 weeks. They both stressed how this gave them new perspectives and insights about teachers, students, and school life in general.

One of these EPs described:

12 students in a class just created a completely different atmosphere and had a very positive impact. The whole school was characterized by a calm in the air, and silence ruled in classes. To avoid teacher shifts, the same teacher taught the same classes the entire day, which also gave students a sense of predictability and continuity.

The same EP added:

It was interesting to see that school days were shorter and there was less traditional teaching. Nonetheless, many teachers told me that they had a clear feeling that student learning outcomes were better than usual because of the reduced number of students in the classrooms. I think that both students with and without special needs got something positive out of the reduced class sizes.

Intuitively, it is hard to argue with claims that class size matters and that the more students a teacher is responsible for, the harder it is to teach. Yet, the issue of class sizes is surprisingly controversial. Although, it is difficult to isolate the effect of class size methodologically, there is research evidence suggesting that students from small classes achieve better academic results. But decreasing class sizes also comes with a substantial price tag, and research evidence also points to high-quality teaching as more important than class size. Local authorities are often facing strict budget constraints, and EPs are used to facing budgetary pressures (Szulevicz \& Tanggaard, 2014). Interestingly, the reopening gave new perspectives on different economic priorities, as expressed by an EP:

It really became clear to me how much context matters. Instead of blaming the kids, we should look at their surroundings. That's not new to us. But we have seen that many of our students thrive in smaller groups. So instead of segregat- 
ing these children in special education classes that are much more expensive, we could reduce class sizes and thereby succeed in including them.

The reduced class sizes after the reopening thus gave food for thought in relation to the organization of and sizes of classes, but the EPs also identified how the lockdown and reopening gave new insights about students' special needs:

Overall, the corona outbreak has taught us something about resilience. When you as an educational psychologist is surrounded by many fragile children and children with special needs, you easily tend to focus on their difficulties. Yet, most children tackled the lockdown and reopening of schools much better than expected.

The COVID-19 pandemic is putting new and unforeseen pressures on all of us. Nonetheless, children do not always react in anticipated ways. The EP suggests that professionals (teachers and EPs (and probably parents)) tend to be biased toward expecting more vulnerable behavior patterns from children in times of crisis. Yet, many of these children actually handled the situation better than expected from them.

\section{Sub-theme 2: the Deregulated School}

The headline of this paragraph is obviously a bit self-contradictory as the reopening of schools, on the one hand, was marked by several measures to suppress COVID-19 restrictions. These measures restricted the freedom of movement of students and teachers and limited possibility for social interaction and thus regulated school in hitherto unforeseen ways. On the other hand, several of the interviewed EPs noticed how school life in other aspects seemed more loose and less regulated. One EP expressed:

Each school had more autonomy to shorten school days, and as the same teacher had the same class all day, the timetable was also more flexible.

Another EP added:

The teachers clearly felt less pressure from the administration and local authorities in relation to learning objectives and student learning outcomes. In that sense, the corona kind of paused accountability measures in schools, and I think it was a kind of relief for the teachers. During the lockdown, the teachers fought with online teaching, but being back with fewer students and less administrative pressure was positive.

While the precautionary measures related to COVID-19 were constraining, the fact that teachers felt less administrative pressure during the reopening relates to an ongoing public debate about Danish schools. In recent years, the view that a limit has been reached in terms of performance pressure, assessment, accountability, and evaluation is gaining ground. The COVID-19 might help to change this by renewing focus on spontaneity, deregulation, local learning communities, and improvisation (Holm, 2020). An EP expressed the same view this way:

I hope that our politicians will learn from this situation. It is evident that schools have been regulated too strictly and that more flexibility and autonomy is needed. 


\section{Discussion}

In many ways, the COVID-19 pandemic exposes the ordinary/extraordinary dialectic that Tateo and Marsico (2019) and Tateo (2020) propose as an analytical tool from cultural psychology to analyze different sociocultural processes. And while Marsico and Tateo originally used the ordinary/extraordinary distinction to analyze meaning-making through which humans turn ordinary semiotic objects into extraordinary ones, the distinction can be used to understand some of the sociocultural processes going on during the pandemic and also of how EPs make sense of children's reactions toward the pandemic. The distinction ordinary/extraordinary is to be understood as a systemic opposition, and not just as either/or. To illustrate this, we can go back to the empirical material, where EPs got new perspectives on the ordinary classroom while working as assistant teachers due to the extraordinary circumstances. From a semiotic cultural psychology perspective, Venuleo et al. (2020) describe the current pandemic as an uncertain social landscape that triggers highly affect-laden or simplified interpretations of the realities. They describe that it is not surprising that people easily fall into affect-laden interpretations in times of crisis, and that the pandemic scenario triggers people into often alarmist sense-making. In his analysis of the use of face masks during the pandemic, Tateo (2020) discusses how the meaning of things and events can be escalated and deescalated through processes of semiotic regulation. But interestingly, the pandemic also triggers a war on sense making and a power struggle about the right to define the effects and consequences of the pandemic. The pandemic is obviously a highly extraordinary event that disrupts existing ways of doing and understanding things, but the situation also calls for a sense of realism and proportion. In that context, Rose et al. (2020) argue that predictions of a "tsunami" of mental health problems as a consequence of the pandemic are overstated. Some people are obviously in need of extra special and mental care, and the disproportionate effects of the COVID-19 on the most disadvantaged in society were perfectly predictable - as also evidenced in this article's "Empirical Results" section. However, from there to interpreting the consequences of the pandemic as leading to a large increase in the number of people suffering from anxiety, depression and stress could be considered an affect-laden interpretation of the consequences. Feelings of anxiety, stress, and despondence are ordinary and expectable feelings in the current situation. But understanding them as diagnosable conditions might be problematic or be evidence of a dominant biomedical understanding of the consequences of COVID-19. Rose et al. (2020) argue that those at greatest risk of developing serious and enduring mental distress are those already impacted by social inequality or those in need of specialized mental health support. For the remainder, talking about a diagnosable mental condition represents an already widespread tendency to psychiatrize and individualize our understanding of fully understandable and expectable reactions to the crisis. A consequence of focusing on mental distress in the population has been a general emphasis on expanding access to specialized mental health care to cope with the consequences of the pandemic. According to Rose et al. (2020), emphasis should also be put on years of underfunding of community mental health services and on rebuilding economic and social supports that have been stripped away over the last years. Rose and his colleagues are writing from a British perspective, but their point globally seems to be pretty generalizable. If we compare their point to this article's empirical material, two things come to mind. Firstly, the highly positive evaluation of the reduced class sizes during the reopening is thought-provoking, as the reduced class sizes both led to better student and teacher wellbeing and a better learning environment. To bring matters to a head, the problem is not the 
student, but the classroom-or the organization of the classroom. If we want to strengthen individual resilience, we should start looking, not so much at the individual child, but rather at the organization of the learning environment. This also points to the fact that questions about vulnerability and marginalization are related to social background, family relations, and individual characteristics. But they are to a great extent also educational questions. The ways learning environments are organized (class size, flexibility, teacher autonomy, performance pressure etc.) clearly have great impact on children's learning and wellbeing.

Secondly, the disproportionate consequences of the pandemic that Rose et al. (2020) described also very clearly stood out in the empirical material of this article. From Qvortrup's et al. (2020a) Danish survey, we know that approximately 20\% of the Danish student population was very negatively affected by the pandemic in terms of loneliness, well-being, and learning outcome. From the empirical material, it seems that students from socially disadvantaged homes were more affected during the lockdown than students with special educational needs. A more in-depth analysis of the consequences is needed and will benefit from ongoing and more extensive research into the dynamics of the consequences of the pandemic.

Interestingly, the general slowing-down of everyday life during the lockdown was not only considered a negative side-effect of the pandemic. The interviewed EPs noticed how the slowing-down also seemed to affect both children and parents in positive ways. The German sociologist Rosa (2020a, b) has analyzed the consequences of the pandemic. He describes how life under the current crisis can be considered an antithesis to our usual accelerated lives, and he even talks about a "forced deceleration" during the crisis. He argues how, what he terms a "massive deceleration of real physical life," leads to feelings of silence and exclusion on the one hand. On the other hand, the forced deceleration also makes us discover new forms of solidarity and new forms of amenability (Rosa, 2020b).

From Rosa's (2020a) standpoint, the current crisis had led to a general loss of ontological security, but the crisis has also created new opportunities for resonance. According to Rosa, resonance is a form of world-relation, in which subject and world meet and transform each other. Whether we in a post-corona landscape actually will learn to decelerate is open to debate and probably highly doubtful. However, Danish professor in Education and teaching Per Fibæk Laursen is fairly optimistic in a recent article:

Danish schools are reaching the limit in terms of performance pressure, assessments and evaluations. The whole idea of meritocratic schooling, involving getting as many pupils as possible to perform well in academic terms, distorts our education system in relation to the needs of society. And it puts psychological pressure on our children and young people, he says.

He explains that COVID-19 might help to change this:

The use of virtual teaching at home has taught a lot of people to appreciate the qualities of face-to-face teaching and dialogue in education. Some high-school students have even been on demonstrations claiming the right to get back to school. So Corona has led to a renewed focus on values such as community, close contact, spontaneity and improvisation. (Holm, 2020: 6)

According to Laursen, the pandemic has the potential to make us build back better by creating more resonant learning environments in which the last decades' regulatory and performance-oriented school regimes might be scaled down for the benefit of teachers and students with and without special needs. 


\section{Conclusion}

At the time of writing (January, 2021), many parts of the world are experiencing massive second wave restrictions, and the pandemic has taken a massive toll on all of us. It is hard to overstate the extent to which the COVID-19 outbreak has affected the world. The focus of this article has been on some of the educational consequences of the pandemic from the perspectives of EPs. I have proposed two different approaches to understanding the pandemic from an educational perspective. The first approach emphasizes how the crisis has deepened existing inequalities and vulnerabilities, whereas the second approach tries to consider the pandemic as an opportunity to rethink education in different and more equitable ways. In some ways, both perspectives are useful to understand the consequences of the pandemic. The interviewed EPs described how the school closures exposed huge social inequalities and as such worsened the learning conditions for the most vulnerable and marginalized children disproportionately compared to their peers of the same age. On the other hand, the interviewed EPs also showed how the pandemic has shed light on the possible need for rethinking schooling in terms of for example class sizes, home school collaboration, teacher autonomy, performance pressure, school accountability, school evaluations, and understandings of student vulnerability. If some of these insights (together with other insights gained during the pandemic) are taken into account in future school development, the current crisis might also present an opportunity to build back better. On the contrary, the pandemic could also be the starting point of the complete opposite development in which we end up building back worse. Educational philosopher, Biesta (2020), expresses such concerns in a recent paper. In the current situation where much education has moved online, Biesta is worried that the pandemic is used as an excuse to promote a digitalization of education in which digital education becomes an imperative for teachers. The consequence of the current focus on the need for digital education is that we tend to forget asking educational questions about the purpose of digital education and how digital education might (or might not) be a purposeful educational answer. Biesta is worried that we are permitting a virus to undermine educational artistry by forcing through a digitalization of teaching that is not educationally justified.

\section{Declarations}

Ethical Approval All procedures performed in studies involving human participants were in accordance with the ethical standards of the institutional and/or national research committee and with the 1964 Helsinki Declaration and its later amendments or comparable ethical standards.

Informed Consent Informed consent was obtained from all individual participants included in the study.

Competing Interests The author declares no competing interests.

\section{References}

Akkermans, J., Richardson, J., Kraimer, M. L. (2020). The covid-19 crisis as a career shock: implications for careers and vocational behavior. Journal of Vocational Behavior, 119:103434. http://www.sciencedirect. com/science/article/pii/S0001879120300592. https://doi.org/10.1016/j.jvb.2020.103434 
Arnove, R. F. (2020). Imagining what education can be post-COVID-19. Prospects, 1-4. Advance online publication. https://doi.org/10.1007/s11125-020-09474-1

Banerjee, D. (2020). The COVID-19 outbreak: crucial role the psychiatrists can play. Asian. Journal of Psychiatry, 50, 1-2.

Biesta, G. (2020). Digital first or education first?: why we shouldn't let a virus undermine our educational artistry. PESA Agora. https://pesaagora.com/columns/digitalfirst-or-education-first-why-weshouldnt-let-a-virus-undermine-our-educational-artistry/

Blundell, R., Costa Dias, M., Joyce, R., \& Xu, X. (2020). COVID-19 and inequalities*. Fiscal Studies, 41, 291-319. https://doi.org/10.1111/1475-5890.12232

Bourdieu, P. (1986). The forms of capital. In J. Richardson (Ed.) Handbook of Theory and Research for the Sociology of Education. New York, Greenwood, 241-258.

Bourdieu, P., \& Wacquant, L. J. D. (1992). An invitation to reflexive sociology. University of Chicago Press.

Brown, S. M., Doom, J. R., Lechuga-Pena, S., Watamura, S. E., \& Koppels, T. (2020). Stress and parenting during the global COVID-19 pandemic, child abuse and amp. Neglect. https://doi.org/10.1016/j. chiabu.2020.104699

Camus, A. (1947/1996). La peste. Gallimard: Saint-Amand.

Hoffman, J. A., Miller, E. A. (2020). Addressing the consequences of school closure due to COVID-19 on children's physical and mental well-being. World Med. Heal. Policy wmh3 365. https://doi.org/ $10.1002 / \mathrm{wmh} 3.365$

Holm, E. F. (2020). Coronakrisen har chokeret, men ikke revolutioneret skolen. Magasinet Asterisk, 4-8, http://www.e-pages.dk/aarhusuniversitet/2372/html5/

Iyengar, R. (2020). Education as the path to a sustainable recovery from COVID-19. Prospects, 1-4. Advance online publication. https://doi.org/10.1007/s11125-020-09488-9

Lawson, M. (2020). Child abuse \& neglect. https://doi.org/10.1016/j.chiabu.2020.104709

Leach, M., MacGregor, H., Scoones, I., Wilkinson, A. (2021). Post-pandemic transformations: how and why COVID-19 requires us to rethink development. World Development, 138:105233. http://www.sciencedirect. com/science/article/pii/S0305750X20303600. https://doi.org/10.1016/j.worlddev.2020.105233

Lupton, D. (2020). Contextualising COVID-19: sociocultural perspectives on contagion (July 27, 2020). Lupton, D. and Willis, K. (eds) The COVID-19 crisis: social perspectives. London: Routledge, Forthcoming., Available at SSRN: https://ssrn.com/abstract=3661226 or https://doi.org/10.2139/ ssrn. 3661226

Malterud, K. (2012). Systematic text condensation: a strategy for qualitative analysis. Scandinavian Journal of Public Health, 40(8), 795-805. https://doi.org/10.1177/1403494812465030

Pesch, M., Julian, M., \& Munzer, T. (2020). Reflections on children with developmental and behavioral challenges who are thriving while sheltering in place. Journal of Developmental \& Behavioral Pediatrics, 41(7), 506-507. https://doi.org/10.1097/DBP.0000000000000848

Qvortrup, A., Christensen, J., \& Lomholt, R. (2020a). Elevers mestringsoplevelser og self efficacy under nødundervisningen i forbindelse med Covid-19-skolelukningerne. Learning Tech, 5(7), 12-39. https://doi.org/10.7146/lt.v5i7.120633

Qvortrup, A., Qvortrup, L., Wistoft, K., \& Christensen, J. (2020b). Nødundervisning under corona-krisen - et elev- og forældreperspektiv. https://ncs.au.dk/fileadmin/NCS/Projekter/Noedundervisning_under_coronakrisen/Corona-rapport_-_generel_rapport_NCS_version.pdf

Rosa, H. (2020a). Interview. Philosophie Magazin, 18 March 2020, https://philomag.de/auf-einmal-sindwir-nicht-mehr-die-gejagten/

Rosa, H. (2020b). Interview. TAZ, 25 March 2020, https://taz.de/Soziologe-HartmutRosa-ueber-Corona/ !5673868/

Rose, N., Manning, N., Bentall, R., Bhui, K., Burgess, R., Carr, S., Cornish, F., Devakumar, D., Dowd, J. B., Ecks, S., Faulkner, A., Ruck Keene, A., Kirkbride, J., Knapp, M., Lovell, A. M., Martin, P., Moncrieff, J., Parr, H., Pickersgill, M., Richardson, G., ... Sheard, S. (2020). The social underpinnings of mental distress in the time of COVID-19 - time for urgent action. Wellcome open research, 5, 166. https://doi.org/10.12688/wellcomeopenres.16123.1

Schroeder, D., \& Gefenas, E. (2009). Vulnerability: too vague and too broad? Cambridge Quarterly of Healthcare Ethics, 18(2), 113-121. https://doi.org/10.1017/S0963180109090203

Singh, S., Roy, M. D., Sinha, C. P. T. M. K., Parveen, C. P. T. M. S., Sharma, C. P. T. G., Joshi, C. P. T. G. (2020). Impact of COVID-19 and lockdown on mental health of children and adolescents: a narrative review with recommendations. Psychiatry Research. https://doi.org/10.1016/j.psychres.2020.113429

Szulevicz, T., \& Tanggaard, L. (2014). Inclusion and budget cuts: the contours of educational psychology in the marketplace. Nordic Psychology (Online), 66(1), 36-52. https://doi.org/10.1080/ 19012276.2014.885762 
Tateo, L. (2020). Face masks as layers of meaning in times of COVID-19. Culture \& Psychology. https:// doi.org/10.1177/1354067X20957549.

Tateo, L., \& Marsico, G. (2019). Framing a theory of ordinary and extraordinary in cultural psychology. In G. Marsico \& L. Tateo (Eds.), Ordinary things and their extraordinary meanings (pp. xi-xxix). Information Age Publishing.

Venuleo, C., Marinaci, T., Gennaro, A., \& Palmieri, A. (2020). The meaning of living in the time of COVID-19. a large sample narrative inquiry. Frontiers in Psychology. 11:577077. https://doi.org/10. 3389/fpsyg.2020.577077

United Nations Educational, Scientific and Cultural Organization. (2020). Global education monitoring report 2020: inclusion and education: all means all, UNESCO, Paris, viewed 30 Oct 2020, https:// unesdoc.unesco.org/ark:/48223/pf0000373718

Publisher's Note Springer Nature remains neutral with regard to jurisdictional claims in published maps and institutional affiliations. 